\title{
ELECTRODEPOSITION OF COPPER ON A COPPER SINGLE-CRYSTAL (100) FACE AND ON A COPPER POLYCRYSTALLINE SURFACE IN THE PRESENCE OF SULPHAGUANIDINE
}

K. SUBRAMANIAN and S. NAGESWAR

Department of Chemistry, Central College, Bangalore University, Bangalore-560 001 (India)

(Received November 20, 1978)

\section{Summary}

In the presence of sulphaguanidine a triangular pyramid growth form changes successively to a layer type of growth which transforms to ridges and then to a polycrystalline deposit on a (100) single-crystal copper substrate. On a polycrystalline copper surface the grain size of the deposit is affected markedly by sulphaguanidine. The change in the growth form and overpotential are explained with the help of IR and X-ray techniques.

\section{Introduction}

It is well known that addition agents are widely used in electroplating baths and that very small quantities of addition agents bring about a marked change in the physical properties of deposits [1 - 3]. The mode of action of addition agents in modifying the form of electrodeposits from an acid copper sulphate bath has been studied by several workers [4, 5]. Almost all workers in the field have observed morphological and electrochemical effects [6]. In most cases only polycrystalline substrates have been used and no systematic attempts have been made to identify the compounds present in order to elucidate the exact function of addition agents. The central problem in the electrodeposition process is to discover the mechanism of crystal growth involving charge transfer, surface diffusion and, finally, incorporation onto the cathode surface.

The purpose of the present study was to elucidate the mechanism of degradation of sulphaguanidine during the electrodeposition of copper. With the help of IR and X-ray techniques, attempts were made to correlate the kinetic parameters such as $b$ and $i_{0}$ and the morphology of the copper deposited onto the (100) plane from the acid sulphate bath. 


\section{Experimental}

The experimental procedure has been described in detail elsewhere [7] . An atomically smooth (100) (checked by X-ray diffraction) face of copper was prepared by electropolishing in a phosphoric acid bath [8]. An electrolytic bath of composition $0.25 \mathrm{M} \mathrm{CuSO}_{4}, 0.1 \mathrm{M} \mathrm{H}_{2} \mathrm{SO}_{4}$ and a known quantity of sulphaguanidine was prepared. The deposition of copper at a given current density was carried out to a thickness equivalent to $10 \mathrm{C} \mathrm{cm}{ }^{2}$. The surface appearance of the copper electrodeposit was examined under a metallurgical microscope at a magnification of $544 \times$.

In order to discover the reasons for change in the mode of growth and in overpotential during copper deposition from acid copper sulphate solutions in the presence of sulphaguanidine, the ability of sulphaguanidine to form a complex with copper was studied using IR spectra and X-ray diffraction (Carl Zeiss Specord by IR 75).

\section{Results}

\subsection{On a polycrystalline surface}

In the absence of sulphaguanidine when copper was deposited at $2 \mathrm{~mA}$ $\mathrm{cm}^{2}$ on a polycrystalline surface the deposit consisted of grains as shown in Fig. 1. When the cencentration of sulphaguanidine in the bath was changed from $10^{20}$ to $10^{11} \mathrm{~mol} \mathrm{l}^{1}$ the grain size decreased (Fig. 2). Similar results were observed at 5,10 and $15 \mathrm{~mA} \mathrm{~cm}^{2}$. At very high concentrations of sulphaguanidine the polycrystalline copper was highly corroded with pitting. The deposit also appeared dark reddish brown and non-uniform.

\subsection{On the (100) plane}

3.2.1. At $2 \mathrm{~mA} \mathrm{~cm}$

A layer type of deposit was obtained in pure solution when copper was deposited on the (100) face, as observed by earlier workers. When the concentration of sulphaguanidine was $10^{19} \mathrm{~mol} \mathrm{I}^{1}$ the relative distance between layers decreased. At $10^{18} \mathrm{~mol} \mathrm{l}^{1}$ the layer growth changed to a ridge-type growth. With further increase in concentration the ridge growth became polycrystalline.

\subsubsection{At $5 \mathrm{~mA} \mathrm{~cm}$}

The layer growth at this current density was almost the same as that obtained at $2 \mathrm{~mA} \mathrm{~cm}^{2}$. The addition of sulphaguanidine to the bath brought about the same types of change in the mode of growth as were noticed at $2 \mathrm{~mA} \mathrm{~cm}^{2}$. When the concentration of sulphaguanidine was $10^{19}$ mol l $^{1}$ a ridge deposit exactly perpendicular to the layer deposit was observed. On increasing the concentration to $10^{18} \mathrm{~mol} \mathrm{l}^{1}$ large pyramids were observed (Fig. 3). With further increase in concentration patchy non-uniform polycrystalline growth was observed. 

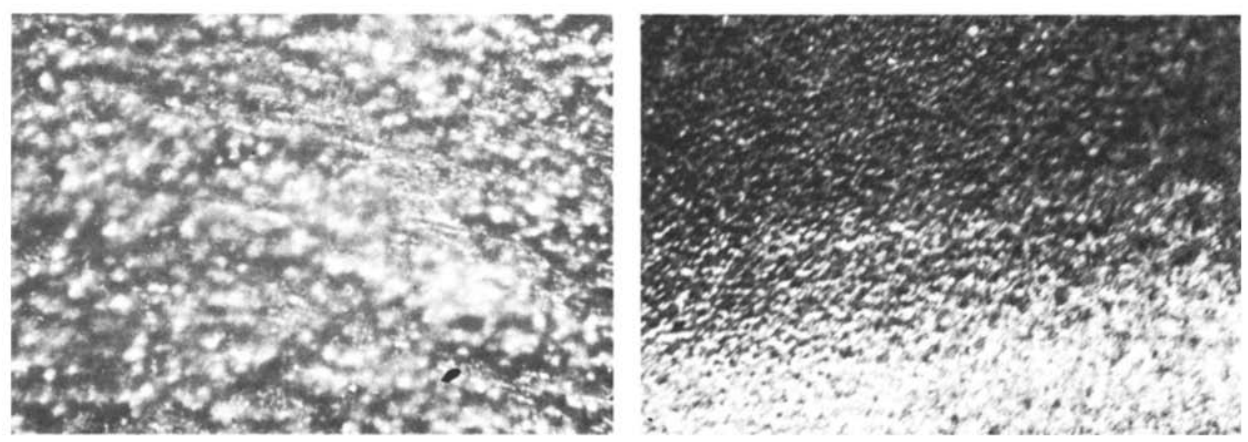

Fig. 1. A polycrystalline deposit deposited onto polycrystalline copper from a pure acid copper sulphate bath at $2 \mathrm{~mA} \mathrm{~cm}{ }^{2}$. (Magnification 544x.)

Fig. 2. Smaller grains of copper deposited on polycrystalline copper from an acid copper sulphate bath containing $10^{11} \mathrm{~mol} \mathrm{l}^{-1}$ sulphaguanidine at $2 \mathrm{~mA} \mathrm{~cm}^{-2}$. (Magnification $544 \times$.)
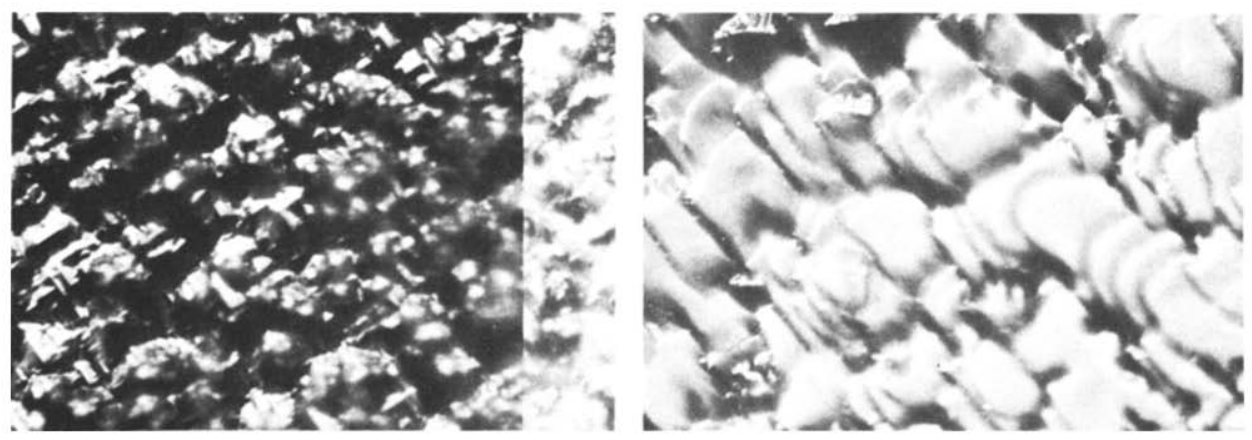

Fig. 3. Larger pyramids of copper deposited on $\mathrm{Cu}(100)$ from an acid copper sulphate bath at $5 \mathrm{~mA} \mathrm{~cm}-2$ in the presence of $10^{-18} \mathrm{~mol} \mathrm{l}^{-1}$ sulphaguanidine. (Magnification $544 \times$.)

Fig. 4. A layer deposit in block form deposited on $\mathrm{Cu}(100)$ from an acid copper sulphate bath at $10 \mathrm{~mA} \mathrm{~cm}^{-2}$ in the presence of $10^{-20} \mathrm{~mol} \mathrm{l}^{-1}$ sulphaguanidine. (Magnification $544 \times$.)

\subsubsection{At $10{\mathrm{~mA} \mathrm{~cm}^{2}}^{2}$}

The deposit obtained from pure solution consisted of layers and small pyramids. A layer deposit in block form was obtained in the presence of $10^{-20} \mathrm{~mol} \mathrm{l}^{-1}$ sulphaguanidine (Fig. 4). On further increase in concentration to $10^{-19} \mathrm{~mol} \mathrm{l}^{-1}$ the layers became ridges (Fig. 5). A ridge type of growth was also observed at $2.5 \times 10^{-19} \mathrm{~mol} \mathrm{l}^{-1}$ (Fig. 6), and at a concentration of $10^{-18} \mathrm{~mol} \mathrm{l}^{-1}$ larger pyramids were noticed (cf. Fig. 3).

\subsubsection{At $15 \mathrm{~mA} \mathrm{~cm}^{-2}$}

Pyramids in the background of layers were observed when copper was deposited at $15 \mathrm{~mA} \mathrm{~cm}^{-2}$ in pure solution. When the concentration of sulphaguanidine was $10^{-20} \mathrm{~mol} \mathrm{l}^{-1}$ large flat layers were observed. On increasing the concentration to $10^{-19} \mathrm{~mol} \mathrm{l}^{-1}$ the layers changed to ridges ( $c f$. Fig. 5). 


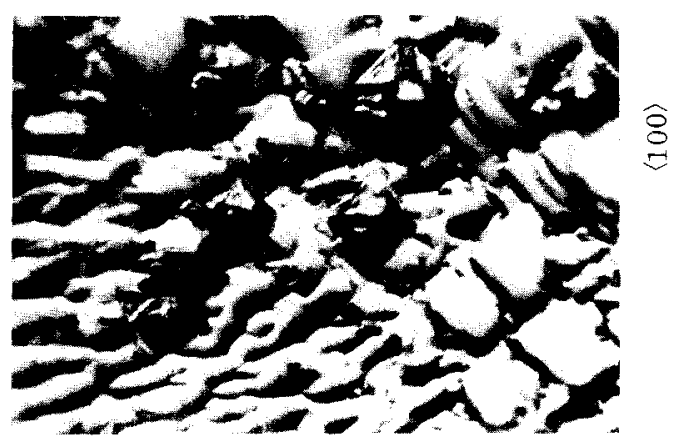

$\langle 110\rangle$

Fig. 5. Layers changing to ridges for copper deposited on $\mathrm{Cu}(100)$ from an acid copper sulphate bath in the presence of $10^{19} \mathrm{~mol} \mathrm{I}^{1}$ sulphaguanidine. (Magnification $544 \times$.)

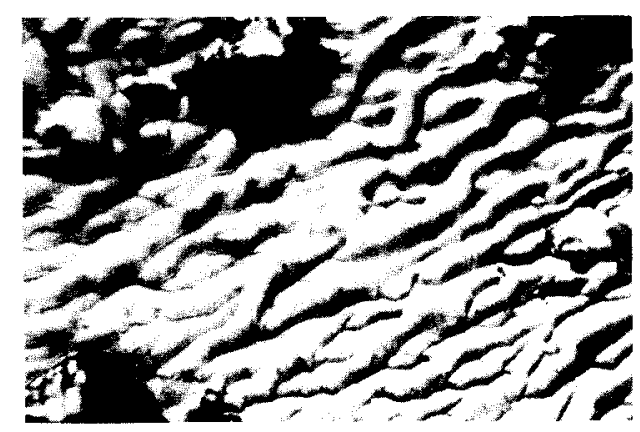

$\langle 110\rangle$

Fig. 6. A ridge, type of deposit deposited on Cu(100) from an acid copper sulphate bath at $10 \mathrm{~mA} \mathrm{~cm}$ in the presence of $2.5 \times 10^{19}$ moll 1 sulphaguanidine. (Magnification $544 \times$.

With further increase in concentration the ridge growth became polycrystalline.

\subsection{Overpotentials}

The overpotentials at all current densities in pure solution initially increased and attained a constant value on the (100) face, as observed by earlier workers [9]. This behaviour was also noticed at low concentrations of sulphaguanidine $\left(10^{20} \mathrm{~mol} \mathrm{l}^{1}\right)$. When the concentration was higher than $10^{18} \mathrm{~mol} \mathrm{l}^{1}$ there was no regularity in the change. When ridge growth was observed the overpotential was almost steady. The Tafel relation holds good only at low concentrations of sulphaguanidine $\left(10^{20}\right.$ mol $\left.\mathrm{l}^{1}\right)$. At higher concentrations it is no longer valid. The available overpotential data for the presence of low concentrations of sulphaguanidine indicate that there is no change in the mechanism of the reaction. The value of $i_{0}$ does not reflect active transfer on single-crystal and polycrystalline substrates at very high concentrations. 


\section{Discussion}

In the presence of higher concentrations of sulphaguanidine the cathodic polarization is lowered. Further, it was observed that the Tafel slope and the $i_{0}$ value changed in the presence of sulphaguanidine at higher concentrations. This indicates that at the current densities investigated the rate-determining step may not be charge transfer. This hypothesis is supported by IR (curve 1(d), Fig. 7) and X-ray (Fig. 8) investigations that revealed the formation of a 1:1 or 1:2 complex of copper sulphaguanidine. It appears therefore that the morphological changes of the deposit are due to complexation and decomplexation effects. The effect of sulphaguanidine on the morphology of copper electrodeposits can be explained with the help of adsorption and complexation theory [10]. A possible reaction mechanism of sulphaguanidine may be
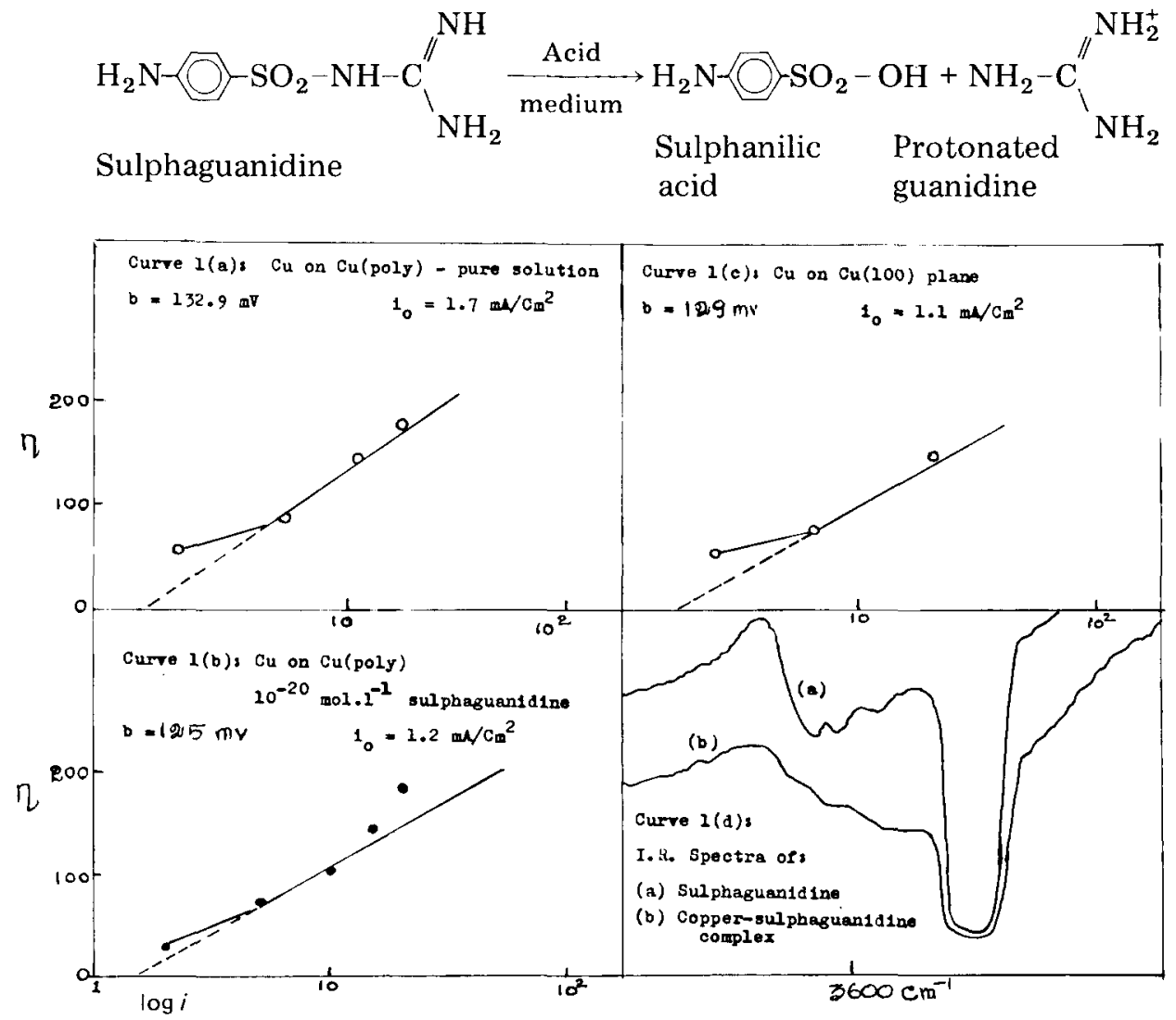

Fig. 7. (a) $\eta$ us. $\log i$ for copper deposited on polycrystalline copper from a pure solution: $b=132.9 \mathrm{mV}, i_{0}=1.7 \mathrm{~mA} \mathrm{~cm}-2$. (b) $\eta v s$. $\log i$ for copper deposited on polycrystalline copper from an acid copper sulphate bath in the presence of $10^{-20}$ mol $\mathrm{l}^{-1}$ sulphaguanidine : $b=125 \mathrm{mV}, i_{0}=1.2 \mathrm{~mA} \mathrm{~cm}^{-2}$. (c) $\eta v s$. $\log i$ for copper deposited on $\mathrm{Cu}(100)$ : $b=129 \mathrm{mV}, i_{0}=1.1 \mathrm{~mA} \mathrm{~cm}^{-2}$. (d) IR spectra of sulphaguanidine and copper-sulphaguanidine complex. 


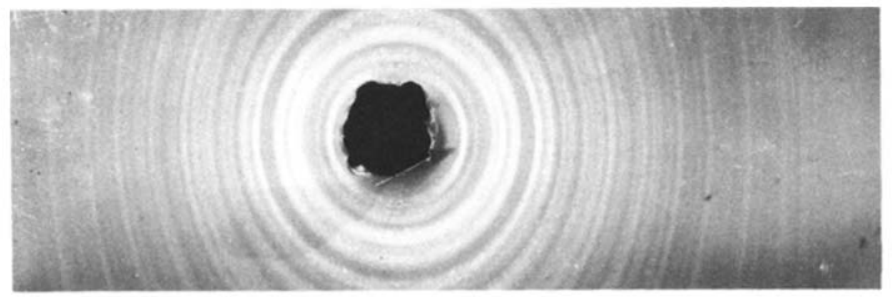

(a)

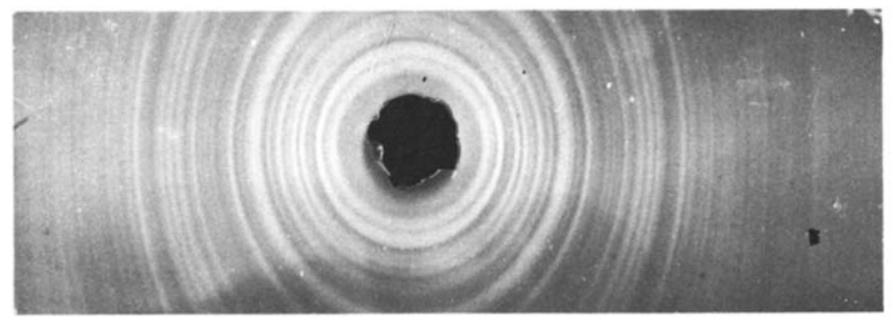

(b)

Fig. 8. Powder X-ray diffraction patterns of (a) pure sulphaguanidine and (b) copper sulphaguanidine complex. (Reich Seifert SO Debye Flex-1000 (diameter $55.4 \mathrm{~mm}$ ) with filtered copper radiation, $30 \mathrm{kV}, 2 \mathrm{~mA}, 1 \mathrm{~h}$.)

With the help of this mechanism it can be assumed that sulphaguanidine or a derivative in acid medium may form a complex which becomes adsorbed on the copper surface, resulting in a change in $\eta$ and $i_{0}$. The growth sites are covered by adsorbed species. The layer type of deposit obtained in pure solution will transform to a ridge type. The step movement may be hindered by complex species during deposition so that the only direction in which the adions can move on the (100) face is the $[110 \mid$ direction, giving rise to the ridge deposits [11]. The change from layers to ridges is also supported by the fact that the overpotential remains the same when ridges are formed. At higher concentrations of sulphaguanidine the electrode surface may become covered by the complex. The copper adions may nucleate and pyramids may grow at higher current densities. At low current densities, however, there will be twinning which will increase beyond a critical value and result in a polycrystalline deposit. 'Thus there will be a transformation from pyramids to layers and then to ridges and finally to polycrystalline deposits.

The Tafel relation (curves 1(a) - 1(c), Fig. 7) holds good at lower concentrations of sulphaguanidine, indicating that charge transfer is the ratedetermining step. At higher concentrations, however, the Tafel behaviour no longer occurs and the Tafel slopes do not indicate active transfer. Thus the actual mechanism may be that copper forms complexes which then undergo degradation.

The observed changes in stretching frequencies and the disappearance of $\mathrm{NH}_{2}$ stretching at $3600 \mathrm{~cm}^{1}$ (curve $1(\mathrm{~d}$ ), Fig. 7) reveals complex formation with copper [12]. It also indicates that the ligand is attached to the 
metal ion through the nitrogen of the sulphanilamide group since the stretching frequency characteristic of the sulphanilamide group has been broadened.

X-ray patterns of the pure drugs (Fig. 8(a)) are amorphous and those of complexes (Fig. 8(b)) are crystalline in nature; there is a change in the fringe width, which also supports the suggested mechanism.

\section{Acknowledgments}

The authors are grateful to the University Grants Commission, New Delhi, for financial assistance and to Professor G. K. N. Reddy for his kind encouragement. The authors also thank Dr. H. Manohar of I.I.Sc., Bangalore, for X-ray photographs.

\section{References}

1 H. Fischer, Z. Elektrochem., 54 (1950) 459.

2 A. Damjanovic, T. H. V. Setty and J. O’M. Bockris, J. Electrochem. Soc., 113 (1966) 129.

3 D. R. Turner and G. R. Johnson, J. Electrochem. Soc., 109 (1962) 798.

4 H. Schnieder, A. J. Sukava and W. J. Newby, J. Electrochem. Soc., 112 (6) (1955) $568-570$.

5 S. C. Barnes, J. Electrochem. Soc., 113 (1964) 296.

6 N. A. Economov, H. Fischer and D. Trivich, Electrochim. Acta, 2 (1960) 336.

7 S. Nageswar, Surf. Technol., 6 (1977) $49-56$.

8 P. Jacquet, C. R. Acad. Sci., 201 (1935) $1473-1475$.

9 S. Nageswar and T. H. V. Setty, Proc. Indian Acad. Sci., Sect. A, 71 (6) (1970) 282.

10 H. Fischer, J. Electrochem. Soc. Jpn, 35 (1967) 169.

11 S. Nageswar, Surf. Technol., 6 (1978) $379-383$.

12 L. J. Bellamy, The Infrared Spectra of Complex Molecules, 2nd edn., Wiley, New York, 1959. 